\title{
Guilty, or not guilty?: a short story of propofol abuse
}

\author{
Sangseok Lee
}

Department of Anesthesiology and Pain Medicine, Sanggye Paik Hospital, College of Medicine, Inje University, Seoul, Korea

A 50-year-old man awoke suddenly at 4:30 a.m., stood on his bed, and cried out, "I told you I could not sleep all night!" Thereafter, he tried to find an anesthesiologist to infuse him with the surgical anesthetic propofol because he was convinced it was the only cure for his insomnia. Finally, he died, 65 days later, from an overdose of propofol after his personal physician had infused him with propofol almost every night for 2 months to put him to sleep. The man's name was Michael Joseph Jackson (August 29, 1958June 25, 2009), who was one of America's most famous singersongwriters, more often referred to as the "King of Pop" [1].

Propofol is a short-acting, hypnotic/amnestic intravenous agent. It is used to induce and maintain general anesthesia, sedation for mechanically ventilated patients, and sedation for various other procedures. Propofol has become the most widely used intravenous agent for inducing general anesthesia with its unique properties that allow for rapid recovery and minimal side effects, as compared to many other anesthetics, particularly sodium thiopental. It has no analgesic properties; thus, additional analgesics such as opioids can be combined with propofol for complete anesthesia. Propofol has been called "milk of amnesia", by the general public because of the milk-like appearance of the intravenous preparation.

Various mechanisms have been proposed for the effect of propofol on the central nervous system [2], including that of potentiation of gamma aminobutyric acid $_{\mathrm{A}}$ receptor activity, which slows channel-closing time [3] and blocks sodium channel [4].

Most clinical physicians and even anesthesiologists consider propofol to be a safe and nonaddictive drug. However, after the first report of propofol abuse in 1992 [5], several reports have provided clinical evidence and a molecular basis for its significant potential for abuse [6-8].
Although the mechanism has not been identified completely, sub-anesthetic and anesthetic doses of propofol increase dopamine concentrations in the nucleus accumbens [7], which is the fundamental site of the brain's reward system. This type of response is usually observed among alcohol and other drug abusers and is suggested to result in tolerance to the amount of substance taken [9]. LeSage et al. [10] showed in a rat and primate study of self-administered propofol that it functions as a reinforcer, suggesting that it has potential for abuse.

Because propofol has intrinsic limitations, including a lack of street availability and the requirement for intravenous administration, it is generally believed not to be of interest to drug abusers. However, healthcare providers in Western society can easily become addicted to propofol because of easy access. According to a 2007 survey conducted at the University of Colorado Health Sciences Center, Denver, by Wischmeyer et al. [11], propofol abuse has risen five-fold over the last 10 years.

Patients usually have a feeling of having slept well without pain in cases of propofol sedation for less painful procedures. Therefore, they fail to get interested in the drug; but some patients, predisposed to drug-dependency, could become abusers after repeated administration. Although there are no accurate statistics in South Korea, many people are willing to undergo cosmetic procedures or gastrointestinal endoscopy because propofol is being used. These types of procedures are the main route for propofol abuse by the general South Korean public [12].

However, we are not concerned about the degree of addiction caused by propofol among the general public or whether there is a particular group who is predisposed to its addictiveness. In this issue of the Korean Journal of Anesthesiology, Kim et al. [13] report on the degree of abuse liability for propofol in the general

Corresponding author: Sangseok Lee, M.D., Department of Anesthesiology and Pain Medicine, Sanggye Paik Hospital, College of Medicine, Inje University, 761-1, Sanggye7-dong, Nowon-gu, Seoul 139-707, Korea. Tel: 82-2-950-1171, Fax: 82-2-950-1323, E-mail: sslee@paik.ac.kr (ㄷ) This is an open-access article distributed under the terms of the Creative Commons Attribution Non-Commercial License (http:// creativecommons.org/licenses/by-nc/3.0/), which permits unrestricted non-commercial use, distribution, and reproduction in any medium, provided the original work is properly cited. 
population, and characteristics of the particularly high abuse liability group using subjective surveys, which were conducted on 169 patients who received propofol for sedation during gastric endoscopy for a health medical examination. The authors show that propofol has a higher morphine-benzedrine group score, which represents the euphoric value, than marijuana and a lower pentobarbital-chlorpromazine-alcohol group (PCAG) score, which represents sedation value, than most opioids. They concluded that propofol results in relatively high euphoria and low residual sedative effects and that there are differences in abuse liability of single propofol exposure in the general population. It is very interesting, from the aspect of sedation, that the propofol PCAG score was lower than that of other drugs, which contrasts with observations of addicts who have a "sensation of good rest or sleep", as compared to other drugs.

I would like to emphasize once more that there is a very narrow window between feeling euphoric following propofol administration and becoming unconscious and not breathing. Because healthcare providers have a responsibility for levels of propofol abuse in the general public, it is very important that regular education on the valid use of propofol and preventing propofol abuse should be provided to them. Propofol abuse should be included in the ethics education for physicians and in the guidelines for the management and treatment of propofol.

Several recent reports have stated that some South Korean actresses are currently being investigated for propofol abuse. According to the prosecutors, the female celebrities were continuously administered propofol by various plastic surgeons and dermatologists. One actress has received propofol 126 times and another has received the drug more than 111 times.

Guilty or not guilty?

Who is responsible for propofol abuse?

\section{References}

1. Alan D. Who's to blame for Michael Jackson's death? CNN.com [Internet]. 2013 Sep 24 [cited 2013 Sep 27]; Entertainment: [about 9 p.]. Available from http://edition.cnn.com/2013/09/24/showbiz/michael-jackson-death-trial/?hpt=en_c1.

2. Trapani G, Altomare C, Liso G, Sanna E, Biggio G. Propofol in anesthesia. Mechanism of action, structure-activity relationships, and drug delivery. Curr Med Chem 2000; 7: 249-71.

3. Krasowski MD, Jenkins A, Flood P, Kung AY, Hopfinger AJ, Harrison NL. General anesthetic potencies of a series of propofol analogs correlate with potency for potentiation of gamma-aminobutyric acid (GABA) current at the GABA(A) receptor but not with lipid solubility. J Pharmacol Exp Ther 2001; 297: 338-51.

4. Haeseler G, Karst M, Foadi N, Gudehus S, Roeder A, Hecker H, et al. High-affinity blockade of voltage-operated skeletal muscle and neuronal sodium channels by halogenated propofol analogues. Br J Pharmacol 2008; 155: 265-75.

5. Follette JW, Farley WJ. Anesthesiologist addicted to propofol. Anesthesiology 1992; 77: 817-8.

6. Weerts EM, Ator NA, Griffiths RR. Comparison of the intravenous reinforcing effects of propofol and methohexital in baboons. Drug Alcohol Depend 1999; 57: 51-60.

7. Pain L, Gobaille S, Schleef C, Aunis D, Oberling P. In vivo dopamine measurements in the nucleus accumbens after nonanesthetic and anesthetic doses of propofol in rats. Anesth Analg 2002; 95: 915-9.

8. Zacny JP, Lichtor JL, Thompson W, Apfelbaum JL. Propofol at a subanesthetic dose may have abuse potential in healthy volunteers. Anesth Analg 1993; 77: 544-52.

9. Heinz A, Siessmeier T, Wrase J, Hermann D, Klein S, Grüsser SM, et al. Correlation between dopamine D(2) receptors in the ventral striatum and central processing of alcohol cues and craving. Am J Psychiatry 2004; 161: 1783-9.

10. LeSage MG, Stafford D, Glowa JR. Abuse liability of the anesthetic propofol: self-administration of propofol in rats under fixed-ratio schedules of drug delivery. Psychopharmacology (Berl) 2000; 153: 148-54.

11. Wischmeyer PE, Johnson BR, Wilson JE, Dingmann C, Bachman HM, Roller E, et al. A survey of propofol abuse in academic anesthesia programs. Anesth Analg 2007; 105: 1066-71.

12. Kim DK. Propofol use for sedation or sedation for propofol use? J Anesth 2012; 26: 289-91.

13. Kim JH, Byun HW, Kim JH. Abuse potential of propofol used for sedation in gastric endoscopy and its correlation with subject characteristics. Korean J Anesthesiol 2013; 65: 403-9. 